\title{
Adult Acute Myeloid Leukemia with Maturation
}

National Cancer Institute

\section{Source}

National Cancer Institute. Adult Acute Myeloid Leukemia with Maturation. NCI Thesaurus.

Code C7961.

An acute myeloid leukemia with maturation occurring in adults. 